\title{
A Quick View on Biology of Near Threatened Peacock Eel (Macrognathus aculeatus) in Khulna Region of Bangladesh
}

\author{
Shamima Sultana*, Kamrun Nahar, Joyanta Bir, Manash Kabiraj, Md. Nuruzzaman Khan \\ Fisheries and Marine Resource Technology Discipline, Khulna University, Khulna, Bangladesh \\ *Corresponding author: shamimasultana87@gmail.com
}

\begin{abstract}
The Peacock eel, Macrognathus aculeatus is a near threatened highly valuable small indigenous species in Bangladesh. It is not only toothsome nutritive table fish but also notable aquarium species but still rely on natural stock. Keeping in mind the paucity of information on the biology which is crucial to develop artificial propagation and culture technique of this species, the present research was performed as an attempt to contribute to the information on the taxonomy and other biological aspects of $M$. aculeatus. Total 50 samples were collected from Khulna region during April to May 2014 to assay. The taxonomical study revealed that the total length, standard length, head length, eye diameter, pre and post orbital length; length of dorsal, anal and caudal fin; length of upper and lower jaw; body depth and width, distance between dorsal fin to caudal fin ranged from 17.00-21.00, 15.0019.00, 0.80-3.00, 0.20-0.40, 0.50-2.10, 0.30-1.70, 3.10-6.70, 3.50-6.30, 0.50-1.50, 0.30-1.00, 0.70-1.80, 0.90-2.30, $0.60-1.20,0.70-2.40 \mathrm{~cm}$ respectively, additionally meristic character's formula appeared like D. 19 - 39, A. 11 - 18, C. 29 - 52, L. 11-15 and number of eye spots on dorsal fin, 3-10. Turning to the biological inquiry which showed that the fish weight (g), gonad weight (g), liver weight (g), gut weight (g), gonadosomatic, alimentosomatic and hepatosomatic index and condition factor ranged from 15.10-28.60, 2.32-3.18, 0.029-0.044, 0.64-1.08, 9.69-14.79, 2.58-4.15, 0.11-0.19 and 0.30-0.40 respectably. The mean values of hepatosomatic and alimentosomatic indices persuaded greater liver activity and feeding intensity in M. aculeatus. Moreover, stomach content depicted that the diet of peacock eel composed of small fish species, small prawn, prawn larvae, earthworm, water strider, insects pupae, Metaphire posthuma, Caenorhabditis, sand and mud for instance, which in brief expressed that M. aculeatus is omnivorous in its feeding habits. Indeed, this preliminary research outcome would be utile for the species identification, seed production, developing culture technologies as well as biodiversity conservation of this near threatened fish species.
\end{abstract}

Keywords: near threatened species, taxonomy, condition factor, gonadosomatic index, hepatosomatic index, food habit

Cite This Article: Shamima Sultana, Kamrun Nahar, Joyanta Bir, Manash Kabiraj, and Md. Nuruzzaman Khan, "A Quick View on Biology of Near Threatened Peacock Eel (Macrognathus aculeatus) in Khulna Region of Bangladesh.” American Journal of Zoological Research, vol. 5, no. 2 (2017): 38-46. doi: 10.12691/ajzr-5-2-4.

\section{Introduction}

The Peacock eel, Macrognathus aculeatus is a near threatened highly valuable small indigenous species (Mastacembelidae) in Bangladesh [1]. Different freshwater habitats of Asia and South East Asia are the main distribution area of this species [2]. This species is mainly availability in rivers, canals, beels, and ponds and inundated fields throughout Bangladesh. It is not only toothsome nutritive table fish but also notable aquarium species. Notwithstanding its palatability and consumer preference, a little information is available on the biology of this fish [3]. Focusing the consumers' penchant, nutritional, economic and aesthetic value as well as to preserve the biodiversity of $M$. aculeatus should be protected from being extinct. Biological studies of this species are indispensable for developing suitable breeding and culture technologies. Very little attempt has been made in the country to promote its breeding and culture. Consequently, keeping in mind the paucity of information on the biology of this species, the present study was focused on the taxonomy and other biological aspects like condition factor; gonadosomatic, hepatosomatic and alimentosomatic index, food and feeding habits of M. aculetus [4] which would be utile for the artificial propagation and developing culture technologies of this fish in aquaculture sector.

\section{Materials and Methods}

\subsection{Collection of Samples}

A total number of 50 specimens of $M$. aculeatus were collected from Khulna region during April to May 
2014. Samples were instantly preserved with ice and fixed with 5\% formalin on arrival in the laboratory. The morphometric and meristic characters were studied in Fish Biology Laboratory, Fisheries and Marine Resource Technology Discipline of Khulna University, Bangladesh. Body weight in gram was recorded by electric balance.

\subsection{Taxonomic Study of M. aculeatus}

At first, external morphology was investigated to collect different qualitative feature detail of peacock eel samples. Seventeen morphometric characters viz., body weight, head length, total length, standard length, pre orbital length, post orbital length, anal fin length, dorsal fin length, caudal fin length, upper jaw length, lower jaw length, eye diameter, height of body, width of body, distance between dorsal and caudal fin, length of lateral line, gonad weight, liver and gut weight along with body color were recorded separately. The measurements were taken by using normal centimeter scale, fine pointed divider, forceps and slide calipers and recorded to the nearest centimeter. Additionally, four meristic characters namely anal fin ray, dorsal fin ray, caudal fin ray number and number of eye spots on dorsal fin were recorded separately [5].

\subsection{Biological Study of M. aculeatus}

M. aculeatus samples were dissected by vertical incision on the ventral side for biological study. Gonad, gut and liver were separated and weighted consequently by using electric balance. The digestion of food items was ceased within few minutes by gutting and preserved guts in separate numbered bottles with 5\% formalin. Gonadosomatic index (GSI), Hepatosomatic index (HIS), Alimentosomatic Index (ASI), Condition factor (CF) were determined according to $[6,7,8,9]$; respectively.

$$
\text { GSI }=(\text { Weight of gonad } / \text { Body weight }) \times 100
$$

$$
\begin{gathered}
\text { HSI }=(\text { Weight of Liver } / \text { Body weight }) \times 100 \\
\text { ASI }=(\text { Weight of Gut } / \text { Body weight }) \times 100 \\
\text { CF }=(\text { Body weight } \times 100) / \text { Total length }^{3} .
\end{gathered}
$$

Food particles were identified by systematic status of the chief constituents of the foregut contents using the keys as given by $[10,11,12]$.

\subsection{Data Analysis}

Data were fixed up, analyzed as well as presented in tabular and graphical forms. Mean, range of each type of data and mean of ratios of morphometric characters were estimated in the present study. Linear regression analysis was performed to determine the relations between different characters of the species. All the statistical analysis was done with the aid of Microsoft office excels and KalidaGraph software.

\section{Results}

\subsection{Taxonomic Study of M. aculeatus}

M. aculeatus possessed an elongated, eel shaped and compressed body form with a long fleshy snout with a tri-lobed extremity and a short rounded caudal fin that was separated from dorsal and anal fins. Mouth was positioned ventrally and eyes were small. Part of the body was brownish to yellowish and marked with two long dark bands on either side ventrally. False 'eye' spots were also observed at the base of dorsal fin. Since samples were sampled randomly from different local markets, the samples were obviously of heterogeneous. Thus the proportion would give the real picture. Mean and range of various morphometric characters, body proportions and

\begin{tabular}{|c|c|c|c|c|c|}
\hline Characters & Mean \pm SD & Range & Proportion & Mean \pm SD & Range \\
\hline $\mathrm{TL}$ & $18.63 \pm 0.83$ & $17.01-20.02$ & TL: SL & $1.08 \pm 0.007$ & $1.06-1.09$ \\
\hline SL & $17.33 \pm 0.80$ & $15.00-19.00$ & SL: HL & $8.52 \pm 2.82$ & $6.23-19.50$ \\
\hline HL & $2.20 \pm 0.55$ & $0.80-3.00$ & SL: PrOL & $14.16 \pm 4.75$ & $8.90-31.20$ \\
\hline PrOL & $1.34 \pm 0.37$ & $0.50-2.10$ & SL: ED & $50.09 \pm 8.37$ & $42.50-79.50$ \\
\hline ED & $0.35 \pm 0.05$ & $0.20-0.40$ & SL: PsOL & $22.19 \pm 7.84$ & $10.06-52.00$ \\
\hline PsOL & $0.86 \pm 0.24$ & $0.30-1.70$ & SL: HOB & $12.10 \pm 2.14$ & 8.17-17.33 \\
\hline AFL & $5.34 \pm 0.78$ & $3.50-6.30$ & SL: WOB & $20.40 \pm 2.70$ & $15.50-27.67$ \\
\hline DFL & $5.07 \pm 0.84$ & $3.10-6.70$ & SL: DBDTC & $12.63 \pm 3.58$ & $7.83-22.57$ \\
\hline CFL & $1.31 \pm 0.25$ & $0.70-1.80$ & SL: AFL & $3.30 \pm 0.42$ & $2.89-4.46$ \\
\hline LUJ & $1.08 \pm 0.25$ & $0.50-1.50$ & SL: DFL & $3.49 \pm 0.50$ & $2.81-5.03$ \\
\hline LLJ & $0.77 \pm 0.17$ & $0.30-1.00$ & SL: CFL & $13.74 \pm 2.53$ & $10.44-22.29$ \\
\hline HOB & $1.49 \pm 0.34$ & $0.90-2.30$ & HL: PrOL & $1.67 \pm 0.21$ & $1.43-2.89$ \\
\hline WOB & $0.87 \pm 0.13$ & $0.60-1.20$ & HL: ED & $6.14 \pm 0.97$ & 3.33-7.90 \\
\hline \multirow{3}{*}{ DBDTCF } & & & HL: LUJ & $2.03 \pm 0.19$ & $1.60-2.89$ \\
\hline & & & HL: LLJ & $2.83 \pm 0.29$ & $2.00-3.75$ \\
\hline & & & HOB: ED & $0.24 \pm 0.03$ & $0.17-0.30$ \\
\hline
\end{tabular}
meristic characters of $M$. aculeatus were present in the Table 1 and Table 2.

Table 1. Morphometric characters and proportions of M. aculeatus 
Table 2. Meristic characters of M. aculeatus

\begin{tabular}{lcc}
\hline \multicolumn{1}{c}{ Characters } & Mean \pm SD & Range \\
\hline Number of total dorsal fin ray & $29.34 \pm 4.52$ & $19-39$ \\
Number of total caudal fin ray & $38.50 \pm 5.36$ & $29-52$ \\
Number of total anal fin ray & $14.21 \pm 1.46$ & $11-18$ \\
Round black spot on dorsal fin & $8.06 \pm 1.27$ & $3-10$ \\
Number of total lateral line & $12.91 \pm 0.65$ & $11-15$ \\
\hline
\end{tabular}

Positive linear relationship were observed between various morphometric characters such like standard length with total length $\left(R^{2}=0.98\right)$, dorsal fin length $\left(R^{2}=0.95\right)$, head length $\left(R^{2}=0.90\right)$, anal fin length $\left(R^{2}=0.89\right)$, caudal fin length $\left(R^{2}=0.90\right)$, height of body $\left(R^{2}=0.86\right)$, width of body $\left(R^{2}=0.72\right)$; with pre orbital length $\left(R^{2}=0.92\right)$, eye diameter $\left(R^{2}=0.62\right)$, length of upper jaw $\left(R^{2}=0.91\right)$, length of lower jaw $\left(R^{2}=0.75\right)$; additionally body weight with total length $\left(\mathrm{R}^{2}=0.83\right)$ and standard length $\left(\mathrm{R}^{2}=\right.$ 0.83 ) and height of body with width of body $\left(\mathrm{R}^{2}=0.69\right)$ measurements in the present investigation (Figure 1 Figure 14).

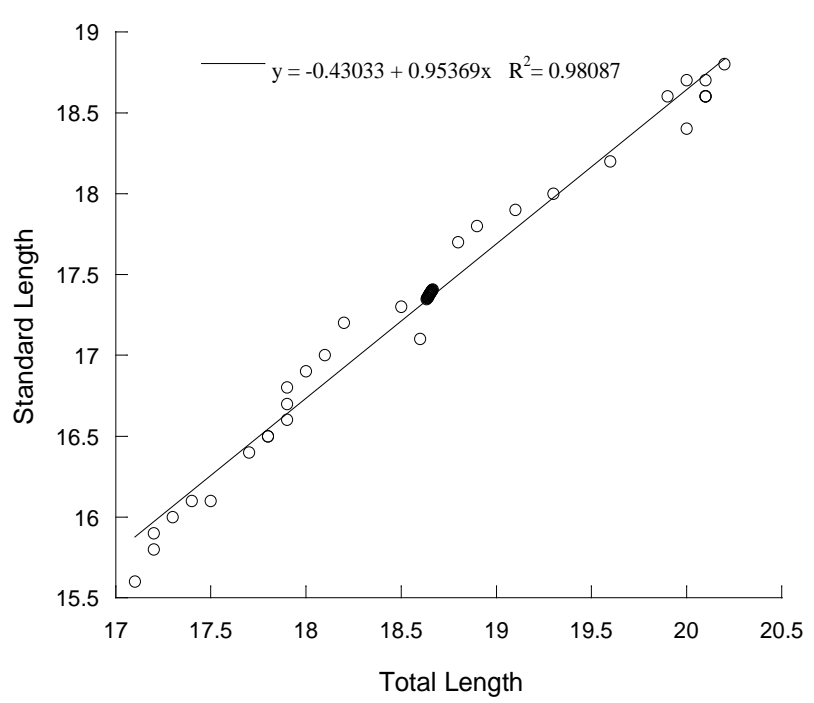

Figure 1. Relationship between total length and standard length

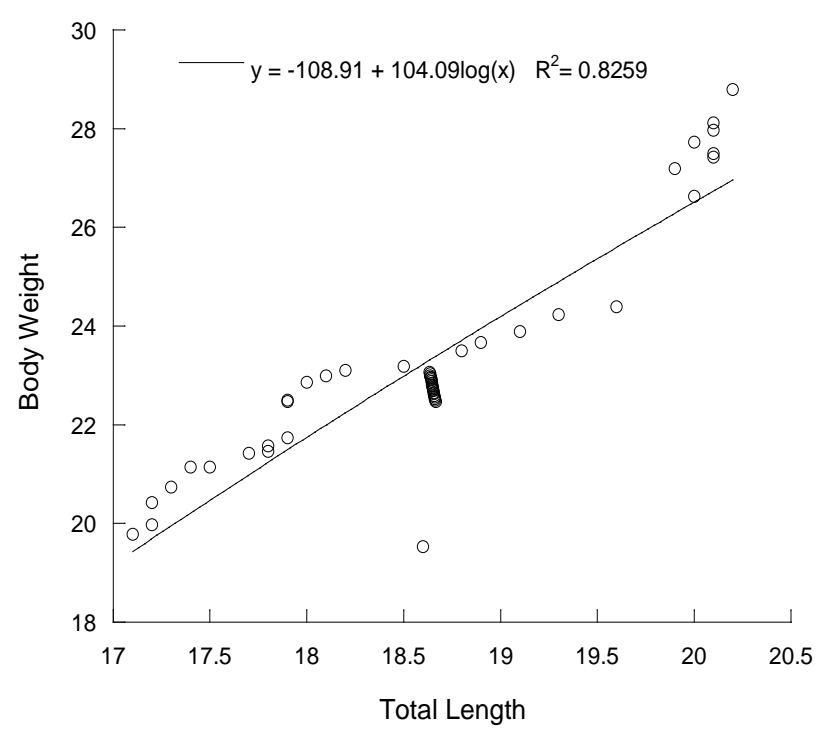

Figure 2. Relationship between total length and body weight

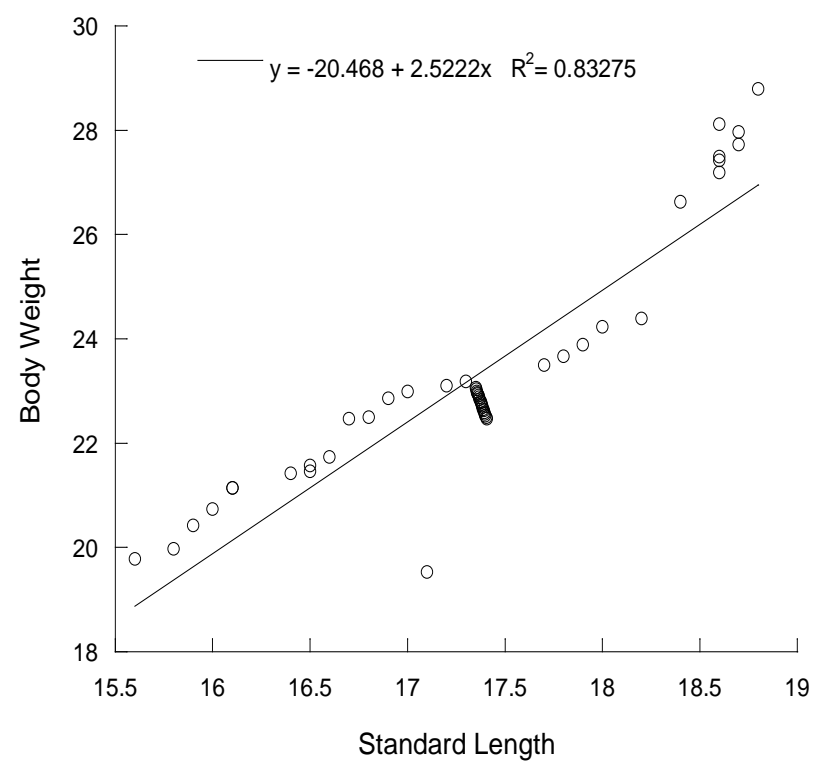

Figure 3. Relationship between standard length and body weight

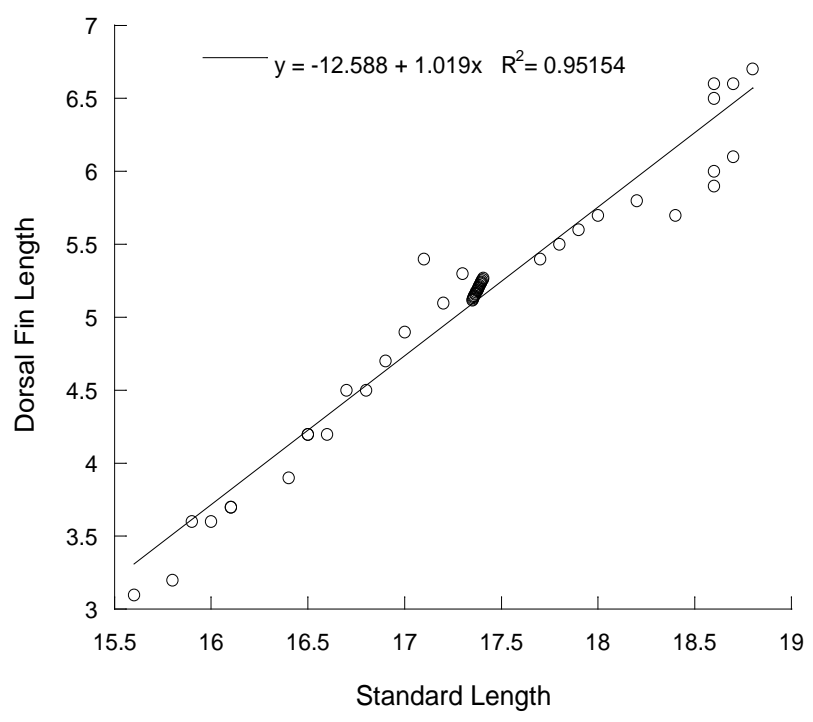

Figure 4. Relationship between standard length and dorsal fin length

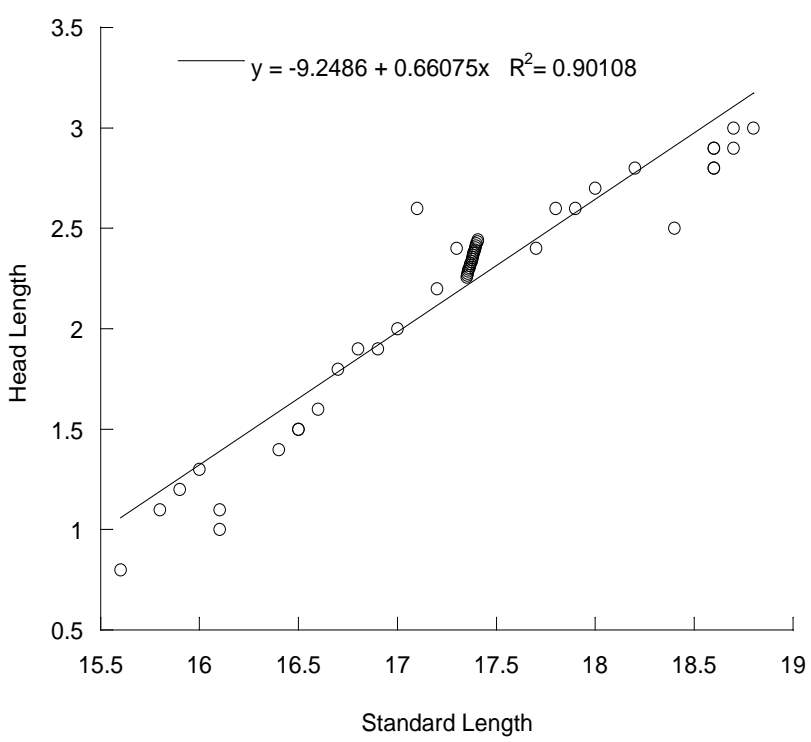

Figure 5. Relationship between standard length and head length 


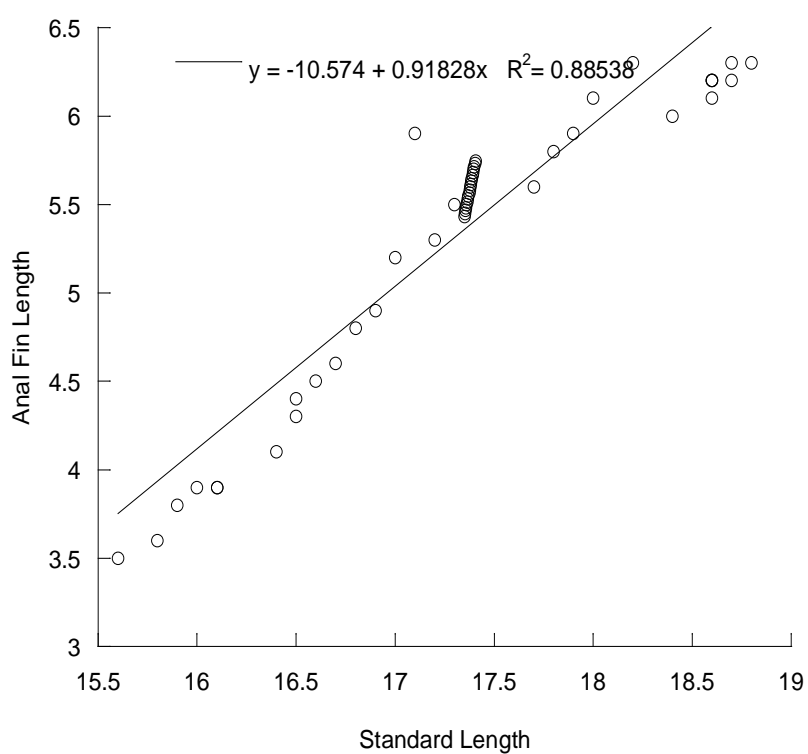

Figure 6. Relationship between standard length and anal fin length

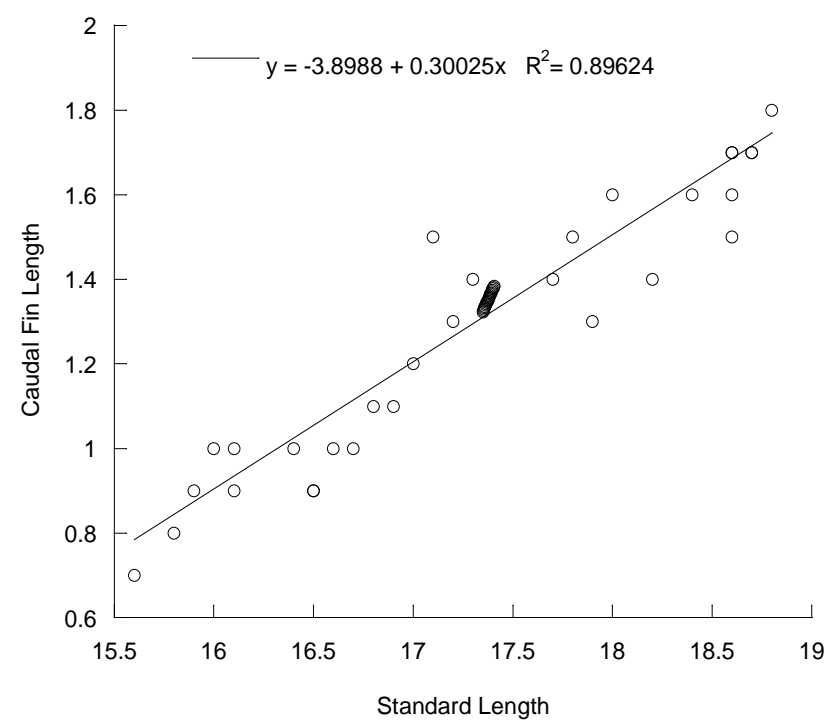

Figure 7. Relationship between standard length and caudal fin length

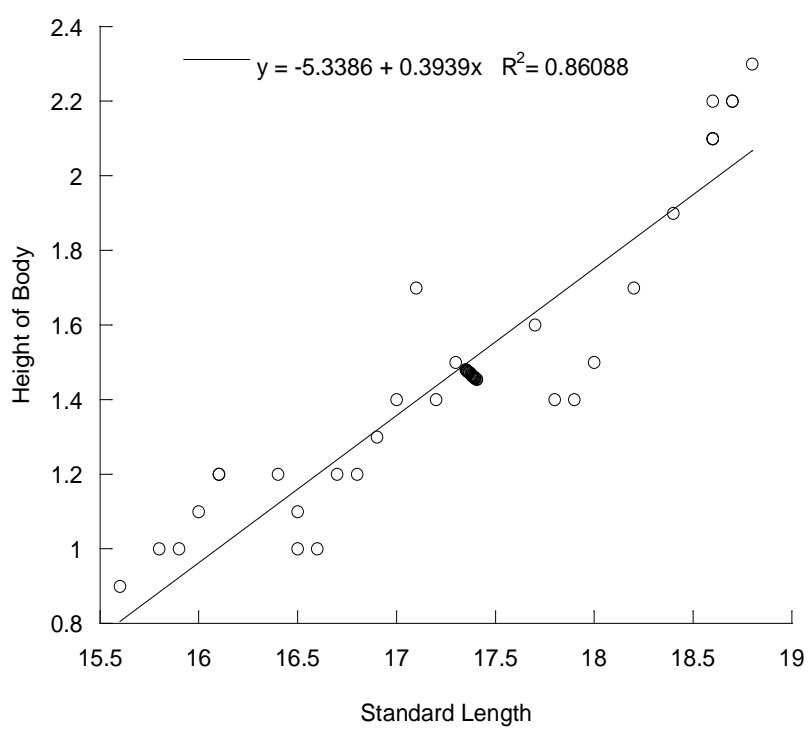

Figure 8. Relationship between standard length and height of body

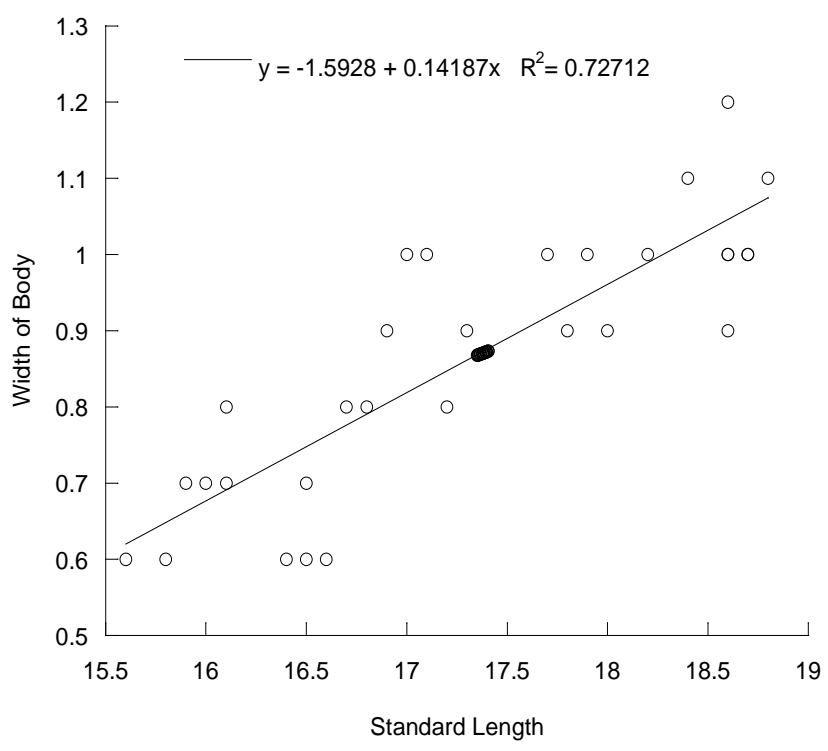

Figure 9. Relationship between standard length and width of body

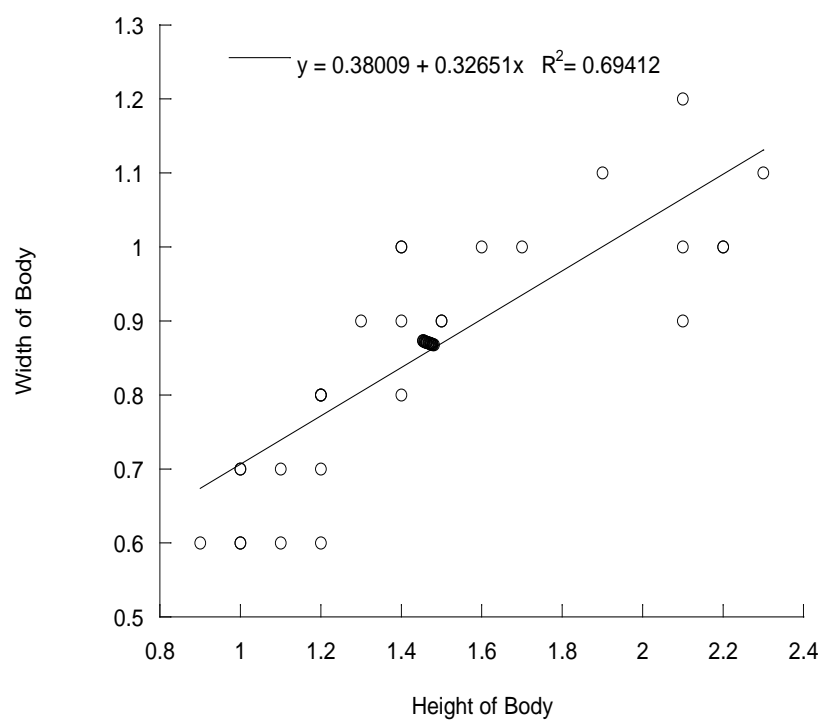

Figure 10. Relationship between height of body and width of body

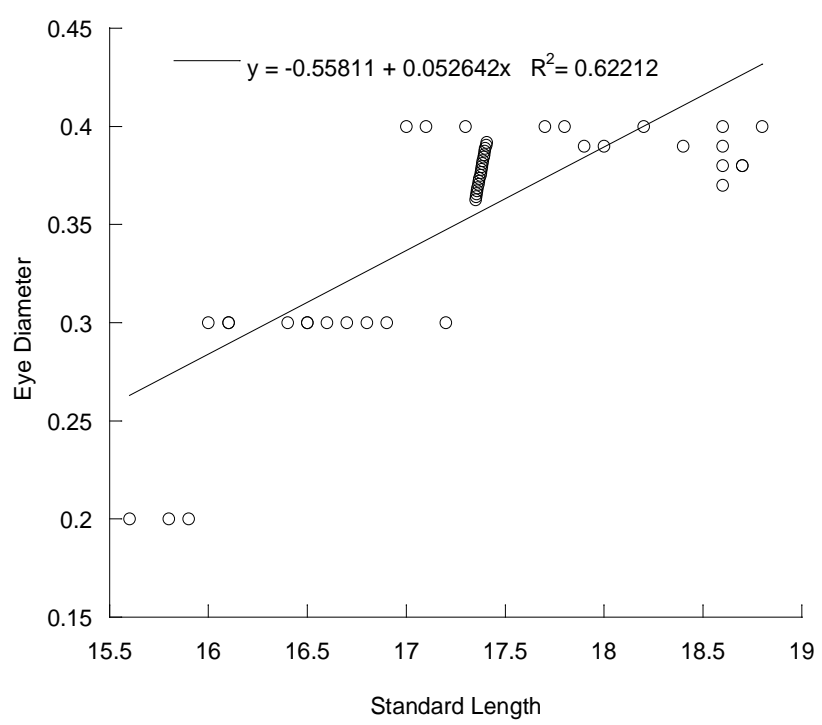

Figure 11. Relationship between standard length and eye diameter 


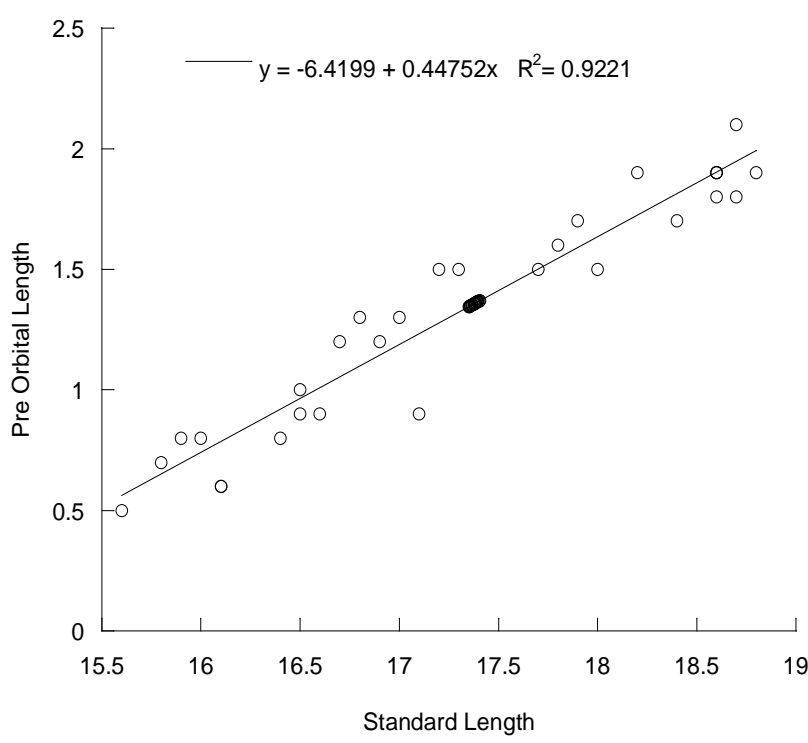

Figure 12. Relationship between standard length and pre orbital length

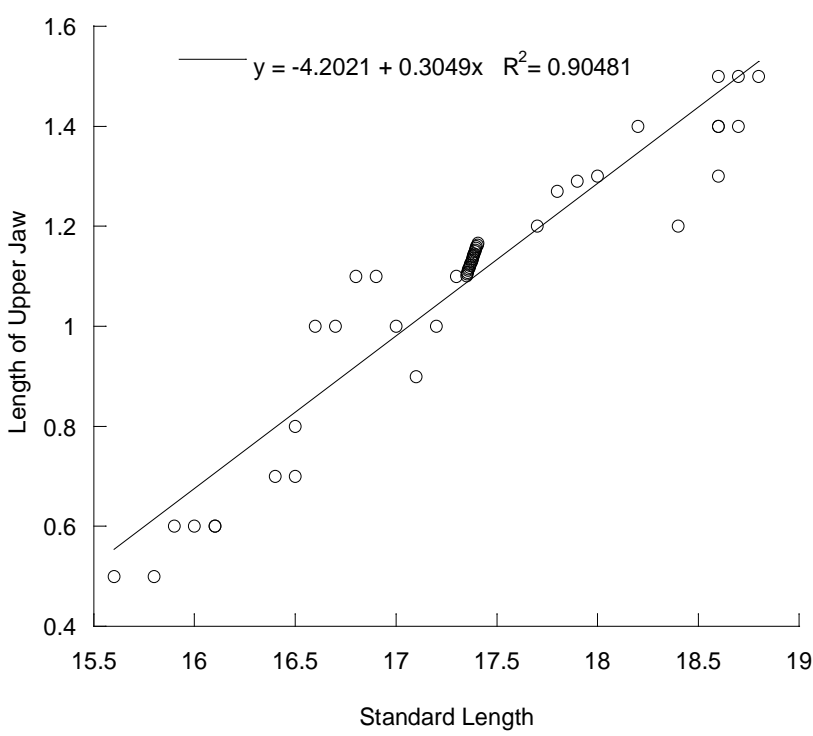

Figure 13. Relationship between standard length and length of upper jaw

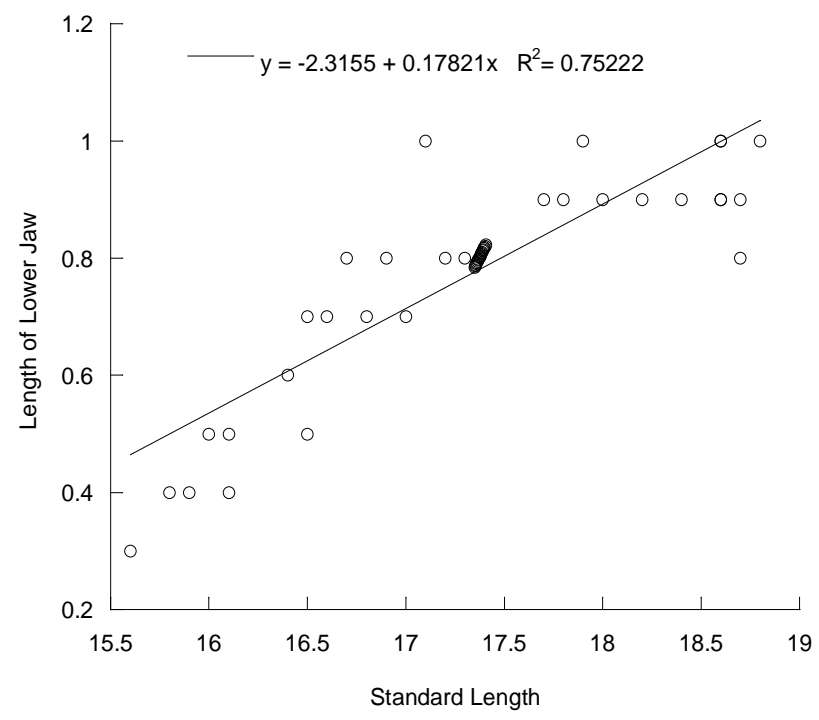

Figure 14. Relationship between standard length and length of lower jaw

\subsection{Biological Study of M. aculeatus}

Mean and range of different biological parameters were mentioned in Table 3. The relationships between fish weight, gonad weight and GSI, liver weight and HSI, gut weight and ASI, and CF were linear (Figure 15 - Figure 27).

Table 3. Biological parameters of M. aculeatus

\begin{tabular}{lcc}
\hline Biological parameters & Mean \pm SD & Range \\
\hline Body weight (g) & $23.25 \pm 2.21$ & $15.53-28.79$ \\
Gonad weight(g) & $2.91 \pm 0.03$ & $2.32-3.18$ \\
Liver weight (g) & $0.034 \pm 0.003$ & $0.029-0.044$ \\
Gut weight (g) & $0.82 \pm 0.073$ & $0.64-1.08$ \\
Hepatosomatic index & $0.15 \pm 0.02$ & $0.11-0.19$ \\
Alimentosomatic Index & $3.53 \pm 0.33$ & $2.58-4.15$ \\
Gonadosomatic index & $12.50 \pm 1.38$ & $9.69-14.79$ \\
Condition factor & $0.36 \pm 0.02$ & $0.30-0.40$ \\
\hline
\end{tabular}

Table 4. Food items found in the gut content of $M$. aculeatus

\begin{tabular}{ll}
\hline Food Groups & Food Items \\
\hline Fishes & $\begin{array}{l}\text { Small Tit punti (Puntius ticto), Mola punti (Puntius } \\
\text { guganio), Kanpona (Awaous guamensis), Bele } \\
\text { (Aplocheilus panchax) }\end{array}$ \\
Insects & Water Strider, Insects pupae \\
Annelid & Earthworm (Metaphire posthuma), \\
Crustaceans & Daphnia, Prawn (Macrobrachium) \\
Nematode & Caenorhabditis \\
Others & Sand and Muds \\
\hline
\end{tabular}

The fishes were all with full stomachs. None of the specimens had an absolutely empty stomach. It was noted that in the case of small fish samples, almost all had their stomachs in full or gorged state during the investigation period. Bloodworms, flake foods, insect larvae, oligochaetes, earthworms, small prawn, prawn larvae, crustaceans, mollusks were observed in the foregut of the samples (Table 4). The stomach contents were found to contain mixed food items. The contents of the rectum were also examined, but since it contained only a well ground pulpy mass, the exact nature of the constituents could not be fully determined. Food items indicated that they are omnivorous in feeding habits.

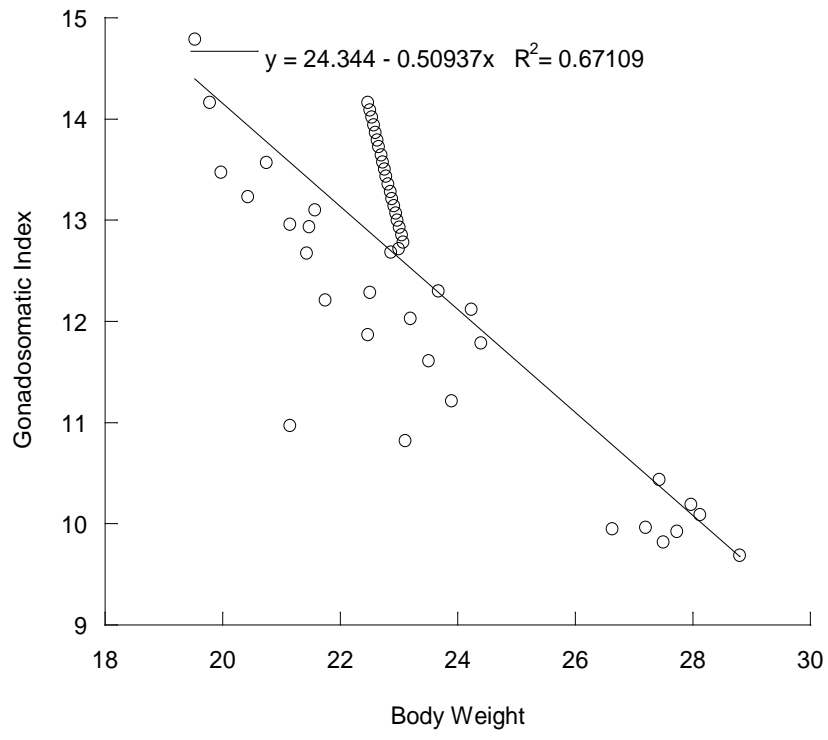

Figure 15. Relationship between body weight and gonadosomatic index 


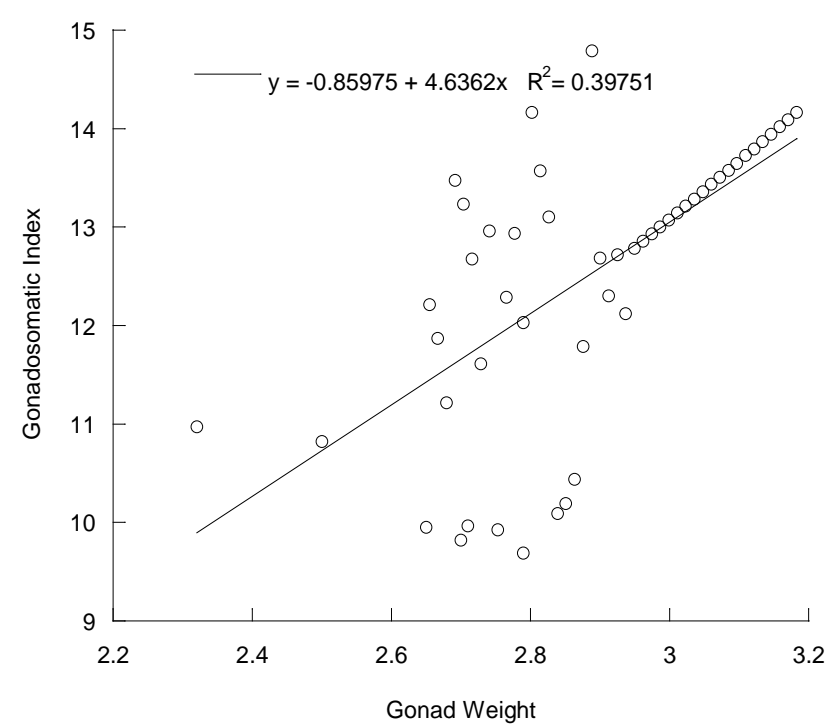

Figure 16. Relationship between gonad weight and gonadosomatic index

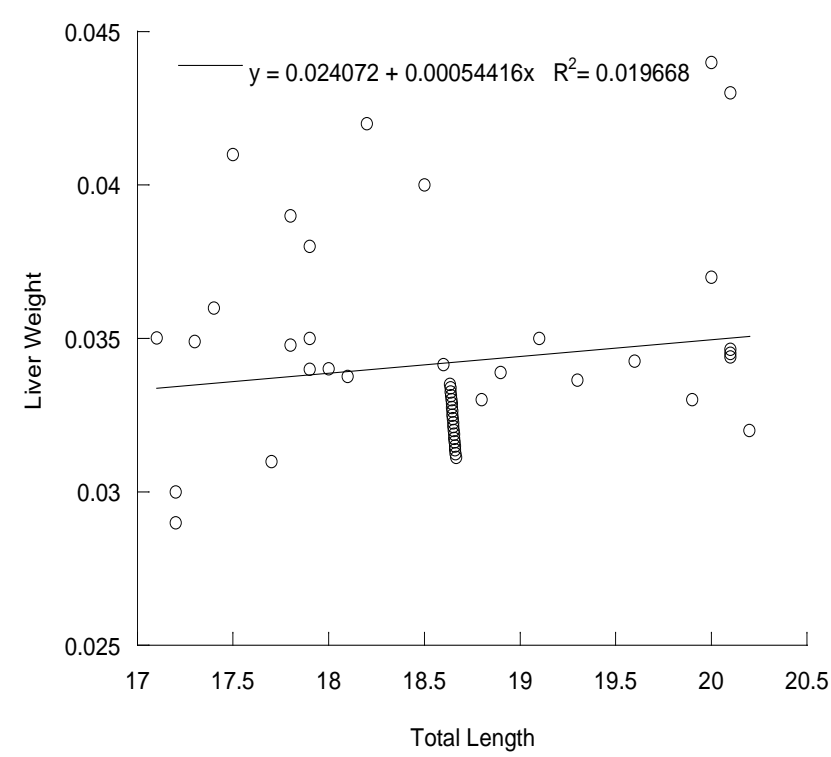

Figure 17. Relationship between total length and liver weight

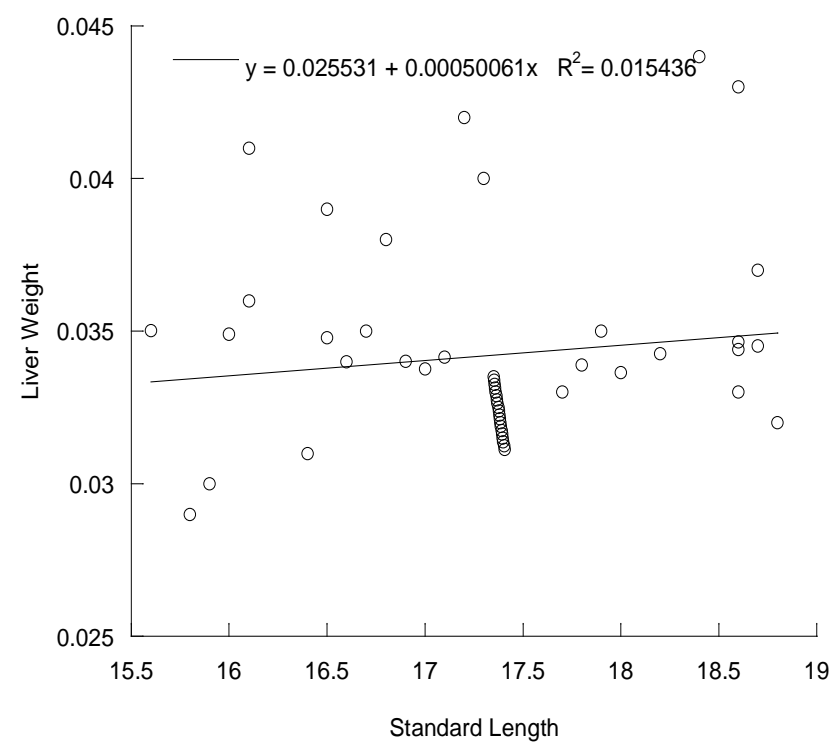

Figure 18. Relationship between standard length and liver weight

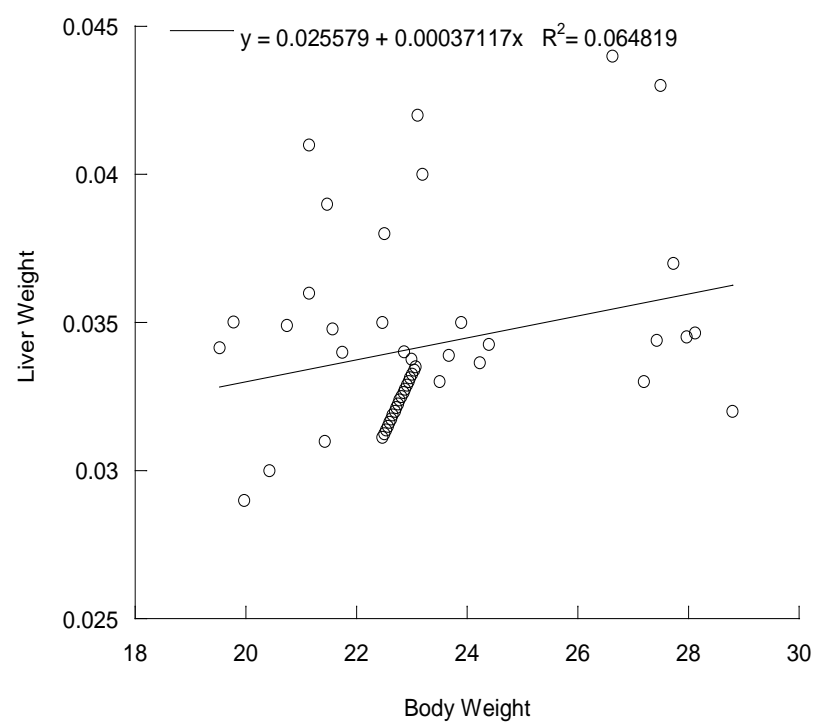

Figure 19. Relationship between body weight and liver weight

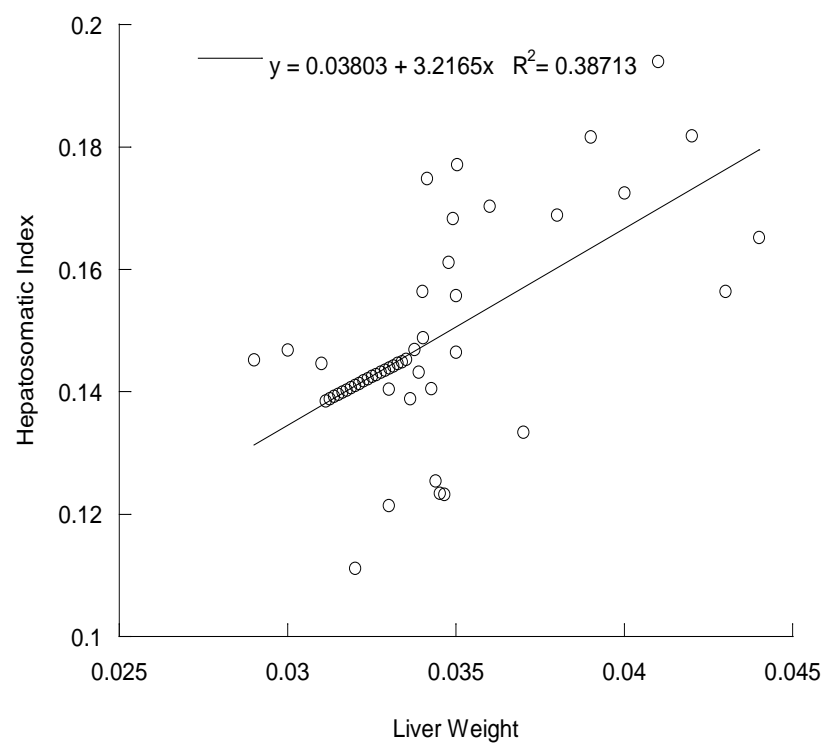

Figure 20. Relationship between liver weight and hepatosomatic index

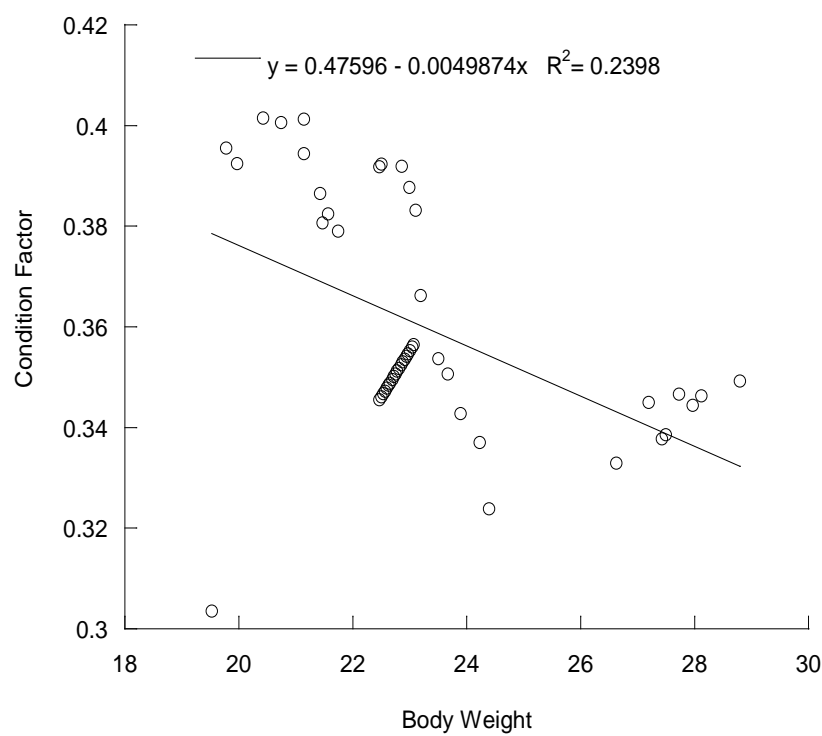

Figure 21. Relationship between body weight and condition factor 


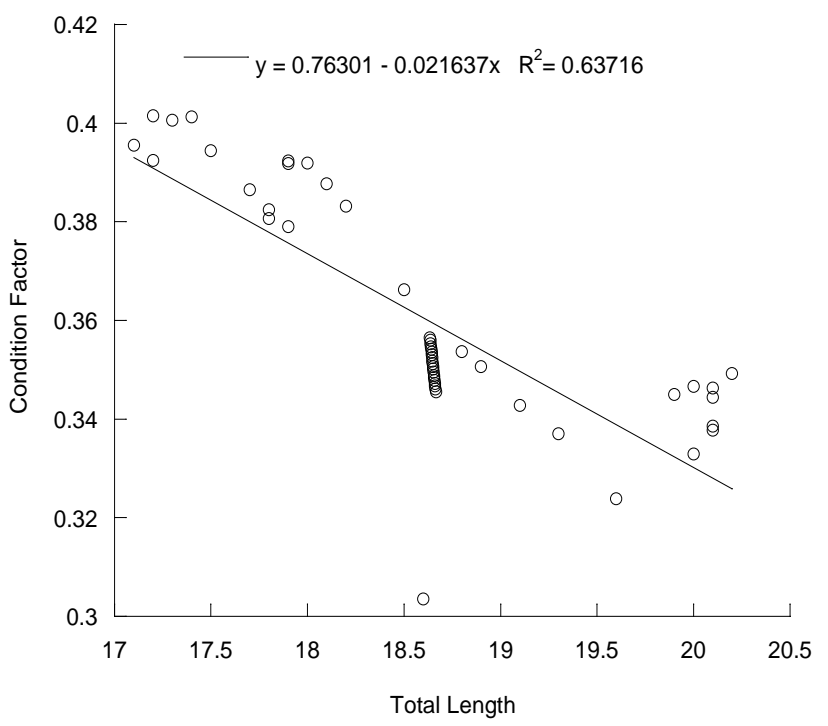

Figure 22. Relationship between total length and condition factor

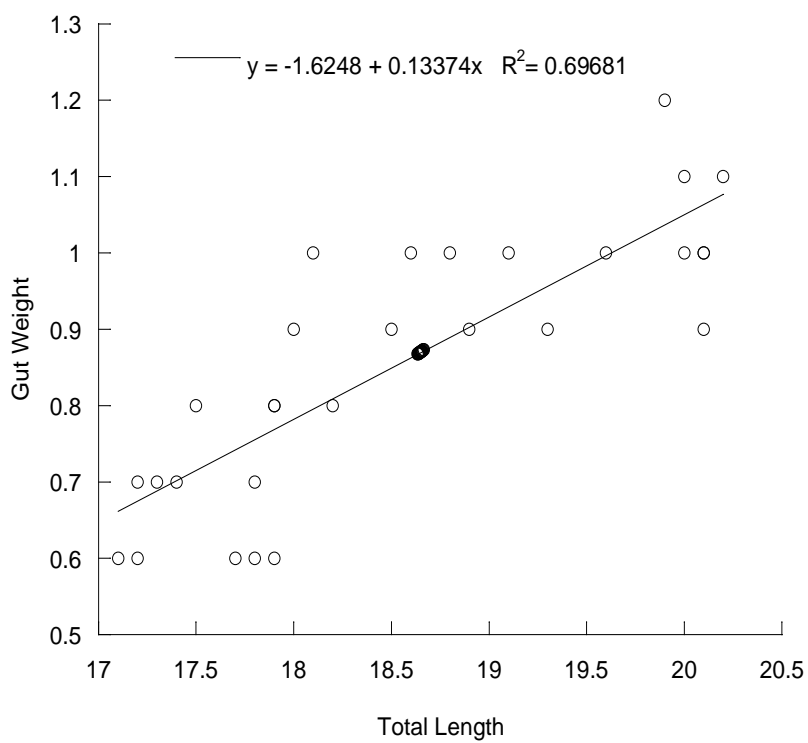

Figure 23. Relationship between total length and gut weight

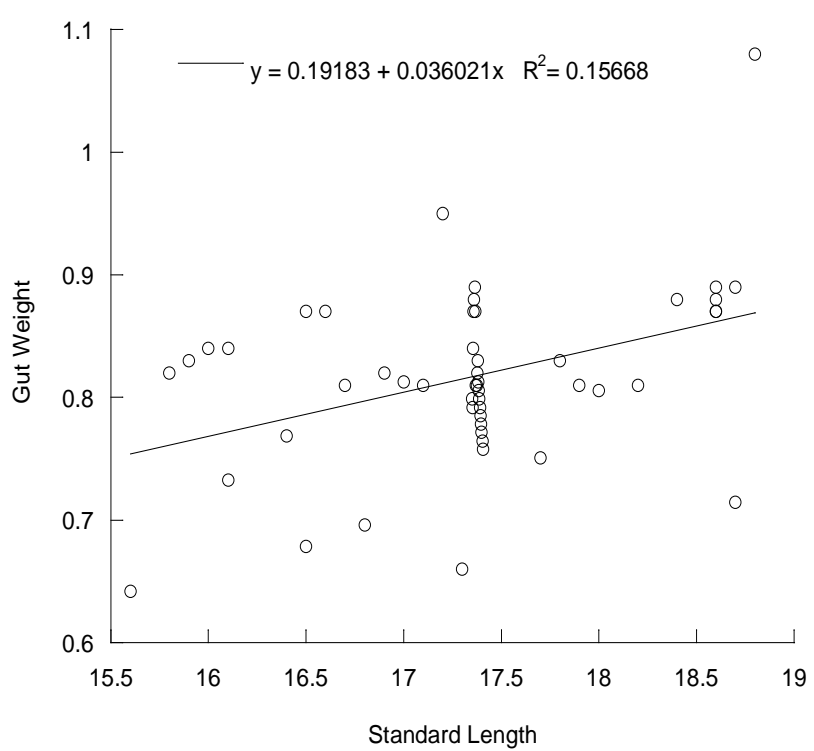

Figure 24. Relationship between standard length and gut weight

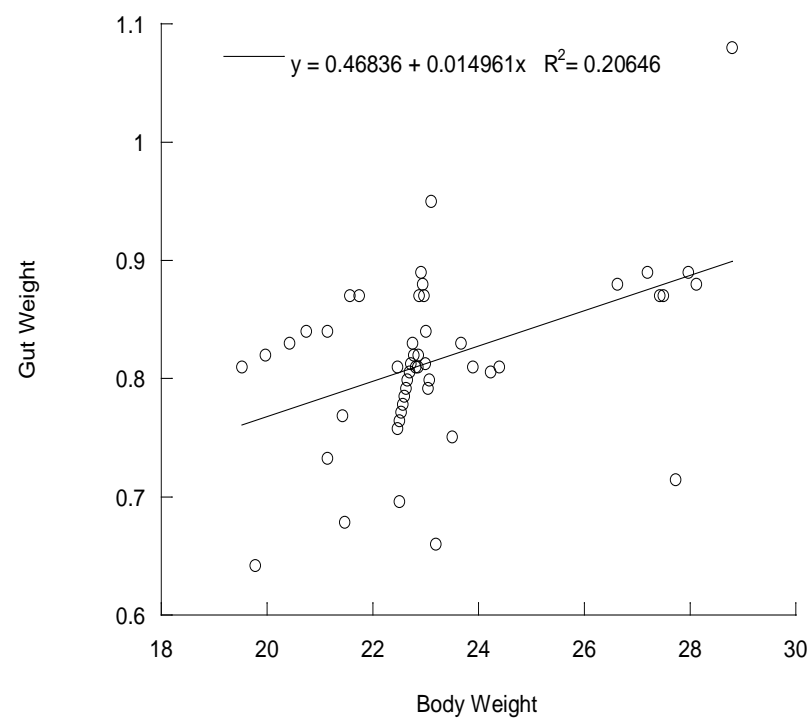

Figure 25. Relationship between body weight and gut weights

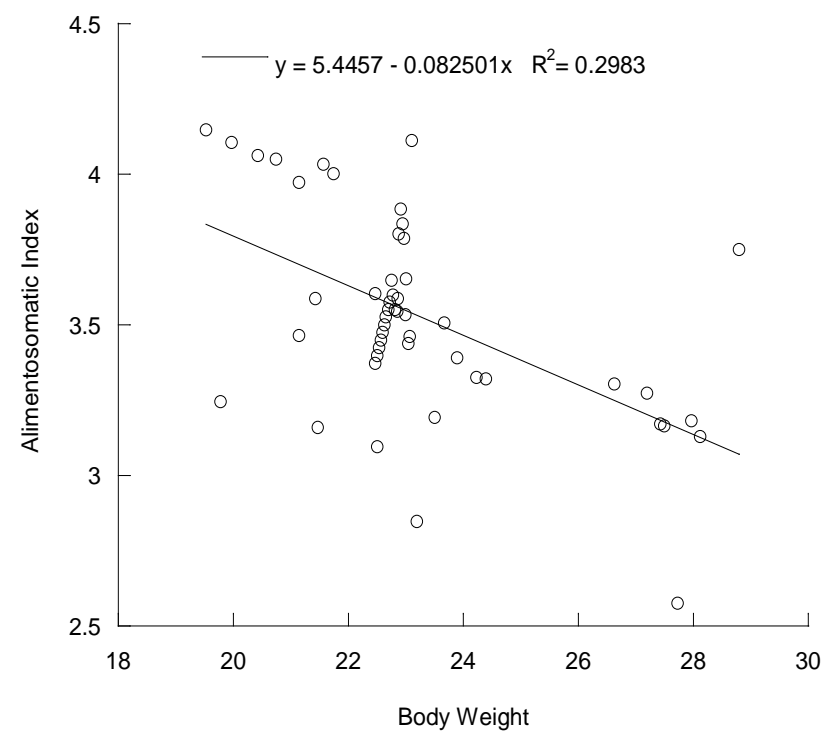

Figure 26. Relationship between body weight and alimentosomatic index

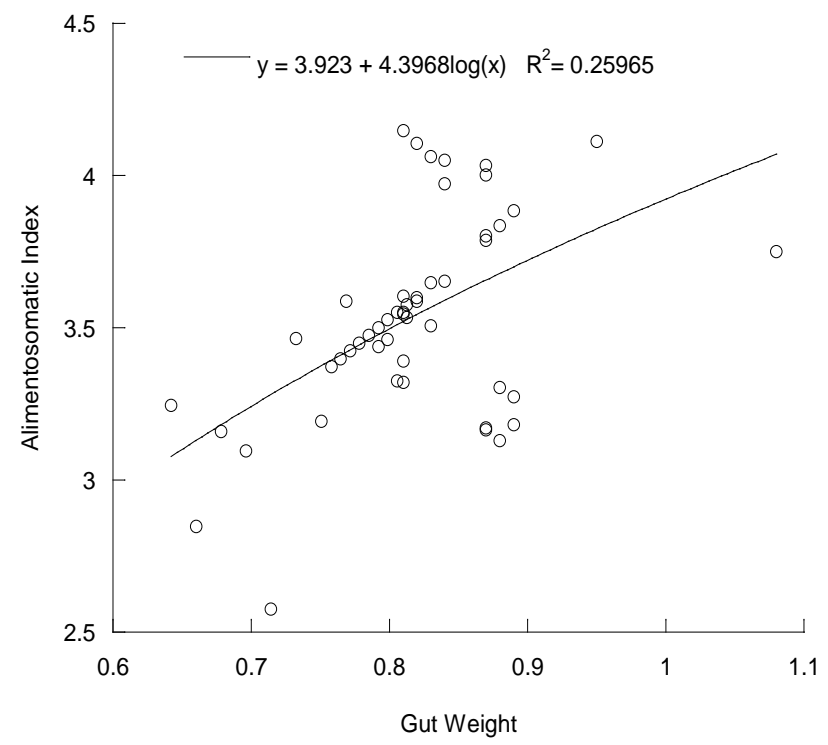

Figure 27. Relationship between gut weight and alimentosomatic index 


\section{Discussion}

The recent research showed that $M$. aculeatus which is internationally known as Peacock eel and nationally as Tara baim, possessed an elongated eel shaped compressed body form with a short rounded tail fin that was separated from long dorsal and anal fin. Additional morphometric character like mouth was positioned ventrally, small eyes and snout with a tri-lobed extremity were observed. Moreover, the ventral part of the body was brownish to yellowish and marked with two long dark bands on either side. Three to eleven ocelli were also observed at the base of dorsal fin. Above mentioned findings were more or less similar to the [2,13] and [14].

The taxonomic study depicted total length and total weight of M. aculeatus ranging from 17.01-20.02 cm and 19.00-29.00 g. The mean total length and total weight were $18.63 \pm 0.83 \mathrm{~cm}$ and $23.25 \pm 2.21 \mathrm{~g}$ respectively. The maximum TL of $M$. aculeatus found in this study was much lower than the maximum recorded value by $[15,16,17,18]$ while slightly higher than [3]. Regional dissimilarities in total length probably depend on the ecological conditions in the areas of research. In addition, [19] and [20] mentioned water temperature can be directly linked to rates of biological production and food availability, as well as to nekton and plankton species composition, both of which influence fish growth. [3] who stated that total length of $M$. aculeatus was ranging from 9.20-19.71 cm and total weight ranging from 15.10-28.60 $\mathrm{g}$, which support the recent findings.

In this research, the fin formula of $M$. aculeatus appeared like the following: D1. 14-20/52-56, A. 3/50-54. The formulas for this species recorded by [21] were D. 16-20/44-54, A. 2-3/44-52; while [13] were D. 17-20/45-50, A. 3/46-50 which is almost similar to the recent findings. Lateral line was present; 11-15. Additionally, a series of 3-10 large black ocelli having white edge was present along base of dorsal.

[22] stated that the average of condition factor (CF) in riverine and beel populations of spiny eel were found to be $0.50 \pm 0.09$, and $0.47 \pm 0.05$, respectively. In this study, mean condition factor of all samples of $M$. aculeatus was found $0.3600 \pm 0.0225$ ranged from 0.3035 to 0.4014 . The condition factor is the relationship between length and weight of fish. The value of it is influenced by several factors. [23] stated that the condition factor is not constant and found to vary in an individual, species or a population having relationship between seasonal changes in the environment and with the changes of physiological conditions of the fishes.

Furthermore, [24] reported the condition factor decreased as weight and growth increases, moreover was maximum at non breeding seasons and reduced in peaked breeding season in Mastacembelus armatus. The condition factor was relatively depended upon food availability and ecological parameters.

[25] reported that the gonadosomatic index (GSI) for fecund striped $M$. aculeatus ranges from $0.44 \pm 0.06$ to $14.40 \pm 1.48$. Mean gonadosomatic index of all samples of M. aculeatus of this research was found to be $12.50 \pm 1.38$ ranging from 9.69 to 14.79 . The reason of this dissimilarities could be season of sample collection. The relationships between fish weight, gonad weight and GSI were linear. The gonadosomatic index itself is more useful to evaluate reproductive potential when used in conjunction with other techniques. The models of potential fecundity as they relate to size (total length and body weight) could be useful when applied to catch statistics of length and weight in populations with known size and age frequency distributions. This application would allow reasonable estimates of potential fecundity for the populations of $M$. aculeatus.

The hepatosomatic index is an indicator of activity of liver. The findings of the present study stated that the mean hepatosomatic index of $M$. aculeatus was $0.034 \pm$ 0.003 ranged from 0.029 to 0.044 . This indicated the greater activity of liver of in $M$. aculeatus. It also concluded that M. aculeatus is omnivorous species. Lack of adequate information on hepatosomatic index of this species encumbers the comparison with other studies. However, [26] stated that omnivorous fishes require more intense liver activity than the herbivorous fish, which support this finding.

The feeding intensity was considered by determining alimentosomatic Index. Present study stated that mean alimentosomatic index of all $M$. aculeatus samples was $3.53 \pm 0.33$ ranged from 2.58 to 4.15 which indicated the greater feeding intensity in M. aculeatus. Likewise, [4] concluded the most active feeding period in both sexes of peacock eel is the stage at which gonad ripens during march to middle April while there was no cessation of feeding in any period of their life.

[27] reviewed in some detail the literature on the food and feeding habits of $M$. aculeatus, as pointed out by them, are variously described as Bloodworms, flake foods, insect larvae, oligochaetes etc. Furthermore, [28] and [4] proposed that Teleostomi (Puntius) was the most preferred prey organisms of peacock eel. Subsequently, other preferred organisms were Esomus, dipterans larvae, prawn, earthworm, brine shrimp and hemipteran larvae according to the criteria of frequency of occurrence. The remaining prey categories of lesser importance were gastropods and some unidentified materials. In other words, the findings of the present research reached in same conclusion. This study expressed that Nematode (Caenorhabditis) were also food item of peacock eel which could engulf accidentally. [29] mentioned the parasites Nematode were much more abundant in rainy season (75\%) followed by summer (62.5\%) and winter (31.81\%) in different parts of the alimentary canal and body cavity of M. aculeatus. In particular, the larger fishes were heavily infected (71.01\%) than medium (53.33\%) and smaller (52.17\%) fishes, which supported our findings. All the outcomes related to food and feeding habit of this research suggested the possibility of the $M$. aculeatus being omnivorous as mentioned by $[4,27,28]$.

\section{Conclusion}

The outcome of this research can be implemental for species identification, captive breeding, conservation of Peacock Eel as well as for set up suitable culture technique. However, in spite of having keen interest, it would be not possible to work on influencing factors like season, area and so on for breeding and feeding ecology 
owing to inadequate facilities. Hence, emphasis should be placed on further investigation on effect of different factors like season, area and condition on breeding biology and feeding ecology in order to identify important factors and times.

\section{Acknowledgements}

We wish to acknowledge all fish sellers as well as staff of Fish Biology Lab, FMRT Discipline, Khulna University for their cooperation in during sample collection and for their assistance and cooperation during the lab work to make this research path more smooth and easier.

\section{References}

[1] World Conservation Union, IUCN. IUCN Red List of Threatened Species. [Retrieved from http://www.iucnredlist.org], 2006, 373.

[2] Das, S.K. and Kalita, N, "Captive Breeding of Peacock Eel, Macrognathus aculeatus", Aquaculture Asia, VIII (3). 17-21. 2003.

[3] Rahman, M.M., Hossain, M.Y., Hossain M.A., Ahamed, F. and Ohtomi, J, "Sex Ratio, Length-Frequency Distributions and Morphometric Relationships of Length-Length and LengthWeight for Spiny Eel, Macrognathus aculeatus in the Ganges River, NW Bangladesh", World Journal of Zoology, 7 (4). 338-346. 2012.

[4] Faridi, A.A., Rizvi, M.M.A. and Serajuddin, M, "Food and feeding habits of peacock eel, Macrognathus aculeatus (Bloch, 1786) from Eastern Uttar Pradesh, India.” International Journal of Fisheries and Aquatic Studies, 4 (4). 130-134. 2016.

[5] Lagler, K.F., Bardach, J.E., Miller, R.R. and May Passino, D.R, Ichthyology, Second Edition, John Wiley and Sons, New York, 1977, 1-506.

[6] Parameshwaran, S., Selvaraj, C. and Krishan, S.R, "The study of the biology of Labeo gonius in confined waters”, Indian Journal of Fisheries, 21 (1). 54-75. 1974.

[7] Delahunty, G. and De Vlaming, V.L, "Seasonal relationship of ovary weight, liver weight and fat stores with body weight in goldfish, Carassius auaratus (L.)” Journal of Fish Biology, 16. 5-13. 1980.

[8] Hynes, H.B.N, "The food of fresh water sticklebacks (Gasterosteus aculeatus and Pygosteus pungitius), with a review of methods used in studies of the food of fishes", Journal of Animal Ecology, 19. 36-58. 1950.

[9] Hile, R, "Age and growth of Cisco, Leucicththys artedi (Le Suer) in the lakes of North eastern high land, Wisconsin". Bulletin of the National Research Council (U.S.) - Washington. 48, 211-217. 1936.

[10] Endmondson, W.T, Freshwater Biology, Second edition, John Wiley and Sons, New York, London, 1959, 389.
[11] Needham, J.G. and Needham, P.R, A guide to the study of Freshwater Biology. Halden-Day, San Francisco, 1962, 205.

[12] Sultana, S., Shah, M.S., Islam, S.S. and Ghosh, A.K, "Taxonomy and other biological aspects of Rhinomugil corsula (Hamilton)", International Journal of Research in Biological Sciences, 3 (3). 123-131. 2013.

[13] Rahman, A.K.A, Freshwater Fishes of Bangladesh. The Zoological Society of Bangladesh, Dhaka, 2005, 273-274.

[14] Bhuiyan, A.L, Fishes of Dacca, Asiatic Society of Pakistan, Dacca, 1964, 118-119.

[15] Smith, H.M, The fresh-water fishes of Siam, or Thailand, Bull, United States National Museum, 1945, 188-633.

[16] Shrestha, J, Fishes, fishing implements and methods of Nepal, Smt. M.D. Gupta, Lalitpul Colony, Lashkar (Gwalior), India, 1994, 150

[17] Vidthayanon, C, Peat swamp fishes of Thailand. Office of Environmental Policy and Planning, Bangkok, Thailand, 2002, 136.

[18] Hossain, M.Y., Ahmed, Z.F., Leunda, P.M., Islam, A.K.M.R., Jasmine, S., Oscoz, J., Miranda, R. and Ohtomi, J, "Length-weight and length-length relationships of some small indigenous fish species from the Mathabhanga River, southwestern Bangladesh." Journal of Applied Ichthyology, 22 (4). 301-303. 2006.

[19] Colerbook, J.M, "Continuous plankton records: phytoplankton, zooplankton and environment, northeast Atlantic and North Sea, 1958-1980", Oceanologica Acta, 5. 473-480. 1982.

[20] Weatherley, A.H. and Gill, H.S, The biology of fish growth. Academic Press, London, UK, 1987.

[21] Shafi, M. and Quddus, M.M.A, Bangladesher Matshaw Sampad, Bangla academy, Dhaka, 1982, 307-308.

[22] Pathak, B.C., Mir J.I. and Serajuddin, M, "Morphometric Variation among Barred Spiny Eel, Macrognathus pancalus (Hamilton 1822), Populations from the Ganges and Brahmaputra River Basin, India by Using Geomorphometrics”. Journal of Biology, 3 (1). 15-20. 2013.

[23] Doha. S. and Dewan, S, "Studies on the biology of Tilapia, length weight relationship and condition factor", Pakistan Journal of Science, 19. 14-23. 1967.

[24] Uthayakumar, V., Sreedevi, P.R., Senthilkumar, D., Munirasu, S., Kiruba, A. and Ramasubramanian, V, "Impact of seasonal variation and feeding on reproductive behavior of fresh water spiny eel Mastacembelus armatus from Cauvery River”, Asian Pacific Journal of Reproduction, 2 (3). 189-195. 2013.

[25] Ali, M.S., Rahman, M.M., Hossain, L. and Mollah, M.F.A, "Studies on the food habits of three species of Mastacembelidae", Bangladesh Journal of Fisheries Research, 7 (1). 43-52. 2003.

[26] Parihar, D. and Saksena, D.N, "The food, feeding habits and condition factor of three freshwater fishes from Tighra reservoir, Gwalior", Journal of Ecophysiology and Occupational Health 10. 13-19. 2010

[27] Roberts, T.R, "A revision of the Asian mastacembelid fish genus Macrognathus", Copeia, 3. 385-391. 1980.

[28] Nikolsky G.V, Ecology of fishes, Academic Press, London, 1963, 352.

[29] Khanum, H., Begum, S. and Begum, A, "Seasonal prevalence, intensity and organal distribution of helminth parasites in Macrognathus aculeatus", Dhaka University Journal of Biological Science, 20 (2). 117-122. 2011. 